Combustion Oscillation Control by Cyclic Fuel Injection

Authors:

George A. Richards (DOE/METC)

M. Joseph Yip (DOE/METC)

E. Robey (EG\&G TSWV, Inc.)

L. Cowell (Solar Turbines, Inc.)

D. Rawlins (Solar Turbines, Inc.)

Conference Title:

1995 American Society of Mechanical Engineers Turbo Expo

Conference Location:

Houston, Texas

Conference Dates:

June 5 - 8, 1995

Conference Sponsor:

American Society of Mechanical Engineers 


\section{DISCLAIMER}

This report was prepared as an account of work sponsored by an agency of the United States Government. Neither the United States Government nor any agency thereof, nor any of their employees, makes any warranty, express or implied, or assumes any legal liability or responsibility for the accuracy, completeness, or usefulness of any information, apparatus, product, or process disclosed, or represents that its use would not infringe privately owned rights. Reference herein to any specific commercial product, process, or service by trade name, trademark, manufacturer, or otherwise does not necessarily constitute or imply its endorsement, recommendation, or favoring by the United States Government or any agency thereof. The views and opinions of authors expressed herein do not necessarily state or reflect those of the United States Government or any agency thereof.

This report has been reproduced directly from the best available copy.

Available to DOE and DOE contractors from the Office of Scientific and Technical Information, 175 Oak Ridge Turnpike, Oak Ridge, TN 37831; prices available at (615) 576-8401.

Available to the public from the National Technical Information Service, U.S. Department of Commerce, 5285 Port Royal Road, Springfield, VA 22161; phone orders accepted at (703) 487-4650. 


\section{DISCLAIMER}

Portions of this document may be illegible in electronic image products. Images are produced from the best available original document. 


\title{
COMBUSTION OSCILLATION CONTROL BY CYCLIC FUEL INJECTION
}

\author{
G. A. Richards and M. J. Yip \\ U.S. Department of Energy \\ Morgantown Energy Technology Center \\ Morgantown, West Virginia \\ E. Robey \\ EG\&G Technical Services of West Virginia \\ Morgantown Energy Technology Center \\ Morgantown, West Virginia \\ L. Cowell and D. Rawlins \\ Solar Turbines, Inc. \\ San Diego, California
}




\begin{abstract}
A number of recent articles have demonstrated the use of active control to mitigate the effects of combustion instability in afterburner and dump combustor applications. In these applications, cyclic injection of small quantities of control fuel has been proposed to counteract the periodic heat release that contributes to undesired pressure oscillations. This same technique may also be useful to mitigate oscillations in gas turbine combustors, especially in test rig combustors characterized by acoustic modes that do not exist in the final engine configuration.

To address this issue, the present paper reports on active control of a subscale, atmospheric pressure nozzle/combustor arrangement. The fuel is natural gas. Cyclic injection of $14 \%$ control fuel in a premix fuel nozzle is shown to reduce oscillating pressure amplitude by a factor of 0.30 (i.e., $-10 \mathrm{~dB}$ ) at $300 \mathrm{~Hz}$. Measurement of the oscillating heat release is also reported.
\end{abstract}

\section{BACKGROUND}

Reduction of combustion oscillations often presents a difficult challenge during turbine combustor development. Combustion oscillations are undesired because the resulting pressure oscillations can shorten component lifetime. Although a significant body of literature on combustion instability exists, practical solutions to instability problems are often clouded by uncertainties over the specific mechanisms driving a given oscillation. Prevention of instabilities during the design and development phase is further complicated because acoustic modes and operating conditions may be different between test rigs and final engine designs. Likewise, operation of a given combustor at new conditions, or with different fuel, may be accompanied by oscillating combustion.

Solution of combustion instability has typically required hardware modifications (i.e., passive control), or limiting the range of engine operation. Both of these solutions are costly, or unacceptable for certain cases. As an alternative, active control has been proposed as a different approach to eliminate combustion oscillations. Active control uses an external control device to mitigate the combustion instability. Active control attempts to limit the combustion oscillation by disrupting (in real time) the processes which create periodic heat release. Combustion which would otherwise oscillate is then stabilized by repeated adjustment of parameters affecting the combustion process. Many different control devices and strategies have been proposed in the last five years. Review articles by Candel (1992) and McManus et al. (1993) describe tests using sound input, periodic boundary layer disruption, spark discharge, and variable air flow as possible control techniques.

Among the various possible control techniques, periodic fuel injection seems to be a practical option for engine applications. The process is shown schematically in Figure 1. A turbine combustor is outfitted with an auxiliary fuel injector capable of adding a portion of the fuel in an unsteady manner. In principle, combustion oscillations could be negated by simply adding fuel out of phase with the established oscillation. Langhome et al. (1990) were the first to attempt this type of control. Tests on a $0.25 \mathrm{MW}$ afterbumer rig showed that closed loop control, using the pressure signal to modulate just $3 \%$ of the total fuel input, could reduce the dominant pressure oscillation by $12 \mathrm{~dB}$. Sivasegaram and Whitelaw (1992) tested a similar concept, again using periodic fuel injection to control the oscillation in an laboratory test rig. In their tests, the injected fuel flow was controlled in both open and closed loop configurations. Depending on the particular control approach, oscillating pressure amplitude was reduced by as much as $15 \mathrm{~dB}$. A recent article by Schadow et al. (1992) reports on a number of control strategies, including fuel input modulation. Various levels of control were 
reported, depending on the specific situation. Finally, Schadow et al. (1993) compared fuel modulation to a slightly different strategy, using a spark discharge to bum a portion of the combustion fuel before entering the main combustion region of a dump combustor. Again, depending on the control conditions, a reduction in the peak pressure amplitude by as much $14 \mathrm{~dB}$ was achieved at one condition. Schadow et al. (1993) also reported the first test results at elevated pressure (1.9 atmosphere).

The above citations provide encouraging evidence that active control using pulsed fuel injection is a viable control technique for turbine combustor oscillations. Contemporary gas turbines have popularized the lean premixing fuel nozzle for pollutant control. Thus, this paper reports application of active control to a premixing fuel nozzle, using natural gas fuel. The approach is similar to the references mentioned above for afterbumers and dump combustors. Fuel pulses are periodically injected into the fuel nozzle, and are shown to produce a significant reduction in oscillating amplitude.

\section{EXPERIMENT DESCRIPTION}

The experimental rig is shown in Figure 2. This atmospheric pressure rig consists of a $76 \mathrm{~mm}$ diameter refractory lined duct, with provision to mount premix fuel nozzles at the top of the duct. The duct geometry includes an extension leg which can be shortened (or lengthened) to support different acoustic modes. These modes can be readily calculated be treating the duct geometry as a classic acoustic branch (Kinsler et al., 1982). Calculating the impedance at the exhaust duct and setting the reactance to zero determines the resonant modes. At gas temperatures of $1475 \mathrm{~K}$, this procedure predicts the following resonant frequencies (in Hertz) 87, 190,300,460,600 Hz, and higher. As will be seen, the fuel nozzle preferentially excites the $300 \mathrm{~Hz}$ mode.

Unsteady pressure was measured using a piezoelectric pressure transducer mounted at the bottom of the extension leg of the combustor duct. Time varying heat release was recorded with a fiberoptic $\mathrm{OH}$ emission probe mounted near the exit of the nozzle. The probe is a $1.6 \mathrm{~mm}$ diameter sapphire rod, connected with a fiber optic cable to an optical filter and photomultiplier tube. The filter is centered at $310 \mathrm{~nm}$, (10 nm bandwidth) and will detect emission from excited $\mathrm{OH}$ radicals which exist momentarily during the combustion reaction. As described by Keller and Siato (1987), the excited state $\mathrm{OH}$ emission is approximately proportional to the rate of combustion in the region viewed by the probe. The sapphire rod accepts radiant emissions from a conic region with a 15 degree viewing angle, extending from the probe tip. The probe was mounted at a slight angle from the duct axis, viewing through the combustion zone. Thus, the $\mathrm{OH}$ measurement is a line of sight measure of the heat release through the portion the flame within the probe viewing angle.

Also shown on Figure 2, thermocouples designated ' $A$ ' and 'B' record the gas temperature (approximately) at the duct centerline, $6.3 \mathrm{~cm}$ and $47 \mathrm{~cm}$ downstream of the fuel nozzle.

A detailed sketch of the fuel nozzle used in these experiments is shown in. Figure 3. A central $12.7 \mathrm{~mm}$ stainless steel tube is used to supply pre-mixed fuel and air to the pilot flame on the nozzle axis. The pilot air flow rate was $0.56 \mathrm{~g} / \mathrm{s}$ with the pilot fuel set to establish the peak flame temperature on thermocouple
'A' (i.e., stoichiometric). It is mentioned that subsequent testing has shown that both the oscillating behavior and control effects are sensitive to the quantity of pilot fuel flow; this is discussed later. The pilot flame is lit with an internal spark electrode approximately $75 \mathrm{~mm}$ upstream of the nozzle exit. The pilot tube is surrounded by the premixing annulus. Natural gas and air are mixed in the annulus upstream of a wire mesh flow straightener. The premixed fuel and air pass through straightfinned swirl vanes, angled 45 degrees from the nozzle axis. For the results described here, premix fuel and air flow rates are $0.4 \mathrm{~g} / \mathrm{s}$ and $9.9 \mathrm{~g} / \mathrm{s}$ respectively, corresponding to a heat input of approximately $20 \mathrm{~kW}$

A bypass route for the premix fuel is provided as shown on Figure 2. The bypass vaive was adjusted to send a small portion of the premix fuel to the bypass port, to induce oscillating combustion; see the discussion below. The total flow rate of premix fuel is unchanged by opening this bypass. The natural gas fuel injector, used for control, is connected through the control port, located across the diameter of the nozzle from the bypass porr. The fuel injector is a commercial automotive fuel injector, used for natural gas powered automobiles. The length of tubing between the bypass valve and the fuel nozzle was $37.5 \mathrm{~cm}$. Likewise, the tubing length between the fuel injector solenoid and the nozzle was also $37.5 \mathrm{~cm}$. These lengths are critical, because acoustic resonance in the tubes contribute to the combustion oscillation, described later.

\section{RESULTS}

The nozzle shown in Figure 3 was initially tested with the control fuel injector turned off, and the bypass valve closed. In this configuration, the nozzle prochuced essentially steady combustion. In contrast to this stable operation, a significant instability was readily established when approximately $15 \%$ of the premix fuel was sent to the bypass port. Figure 4 shows the pressure and OH signal corresponding to this bypass condition. A $4.5 \mathrm{kPa}$ RMS pressure signal is established at $300 \mathrm{~Hz}$. Figure 5 shows an ensemble average of one cycle of the pressure and heat release oscillation. Notice that the pressure has an initial inflection point followed by a further increase in amplitude, while the $\mathrm{OH}$ curve has no corresponding inflection point. The "doublepeaks" appearing in the pressure curve are believed to result from the phase difference between the heat release and acoustics. Because the pressure transducer was not located at the point where combustion occurs, the exact phase relation between pressure and heat release cannot be inferred from Figure 5 .

The exact mechanism driving this oscillation is only briefly discussed here. Given the magnitude of the pressure fluctuations inside the combustor, significant pressure and velocity variations are expected inside the premixing annulus. The acoustic response of the gas in the bypass tube produces a periodic variation in the bypass fuel flow. The resulting oscillation in the premix fuel/air ratio causes a variation in heat release which drives the pressure oscillation. This fuel/air variation has been well-documented in rocket oscillations (Harrje and Reardon, 1972), and in some gas turbine combustors (Kenworthy et al., 1989). Experimental and theoretical work in progress is aimed 
at developing a detailed description of the oscillation mechanism in this nozzle.

Active control of the oscillation was attempted by adding $0.067 \mathrm{~g} / \mathrm{s}$ of natural gas control fuel through the pulse injector. This represents $14 \%$ of the total flow rate of fuel, and produces an overall equivalence ratio of 0.85 . The control fuel injector was operated with a frequency of $50 \mathrm{~Hz}$, and a pulse width of $16 \mathrm{~ms}$. The resulting pressure oscillation in the combustor duct is shown in Figure 6. Notice the injector open duration is shown on this plot by thick lines above the pressure signal. The duration was relatively long compared to the pressure cycle. The added control fuel contributes to the oscillation in the same manner as the by-pass fuel. Comparing Figures 4 and 6 , the added control fuel produced an even larger oscillation. Again, the only difference between these two figures was the addition of control fuel at $50 \mathrm{~Hz}$, with a long pulse duration. Notice in Figure 6 that the heat release $(\mathrm{OH})$ spectra does not show any appreciable signal at the fuel injector driving frequency $(50 \mathrm{~Hz})$. This confirms that the long pulse width is essentially equivalent to steady fuel input.

Without changing any other operating conditions, the effect of shorter pulse width $(7.2 \mathrm{~ms})$ is shown in Figure 7 . Comparing to the previous figure, and Figure 4, the oscillation has been noticeably reduced. Statistical analysis of the waveforms shows that the RMS pressure amplitude was reduced by a factor of 0.30 from the uncontrolled case (Figure 4). Referring to the $\mathrm{OH}$ spectra, the control frequency of $50 \mathrm{~Hz}$ is evident, indicating the control fuel injection is indeed causing a variation in heat release at the control frequency.

Tests were conducted over a range of pulse widths. Figure 8 shows the RMS pressure level as a function of the pulse width, at the driving frequency of $50 \mathrm{~Hz}$. The pulse width is expressed as a percent of the fuel injector period at $50 \mathrm{~Hz}$. The oscillation is seen to drop off dramatically at a pulse width of less than $35 \%$; this is comparable to three periods of the $300 \mathrm{~Hz}$ oscillation: Variation in the pulse width was tested several times to determine the pulse width required for effective control. In practice, a precise value could not be determined; there is some latitude in where the control takes effect. Further tests were conducted at a fixed pulse width, but with a driving frequency between 50 and $80 \mathrm{~Hz}$. The driving frequency had little effect on control until reaching $80 \mathrm{~Hz}$, where the large amplitude pressure oscillations resumed. Tests in progress will map out the required combination of pulse width and frequency needed for control.

Before concluding, it is mentioned that ongoing tests have shown that both the baseline oscillation, and the control behavior are remarkably sensitive to a number of geometric and operating parameters. For example, lowering the pilot tube into the combustion region by as little as $3 \mathrm{~mm}$ could negate the baseline oscillation. Changing the pilot fuel flow by just a few percent or changes in the temperature of the refractory combustor duct could likewise negate (or promote) either the oscillation or the control effect. While the control behavior described here could be qualitatively established by carefully setting flow rates, the quantitative level of the control achieved was affected by apparently minor changes in nozzle geometry (i.e., orientation of the swirl vanes, precise location of the pilot tube, etc.). This sensitivity may be an inherent feature of swirl stabilized flames. In a nozzle similar to the one studied here, Stamer and Bilger (1986) report that even a 0.2 degree misalignment of the central fuel tube can produce significant asymmetries in observed (diffusion) flame structure. Milosavljevic et al. (1990) showed that a swiri nozzle with a central fuel tube can produce both symmetric and asymmetric flame structures. depending on the flow rates. For the present investigation, it is suggested that the (delicate) orientation of flame asymmetries with respect to the bypass or control ports may play a role determining the magnitude of the oscillating or controlled response; this issue is under investigation.

\section{SUMMARY AND CONCLUSIONS}

A $20 \mathrm{~kW}$ atmospheric pressure natural gas combustor has been used to study the active control of combustion oscillations. Combustion oscillations arising from fuel/air variations in a premixing fuel nozzle are controlled by periodic injection of fuel in the premixing zone of the fuel nozzle. Specifically, a $300 \mathrm{~Hz}$ oscillation with $4.5 \mathrm{kPa}$ RMS pressure amplitude was reduced by a factor of $0.30(-10 \mathrm{~dB})$. Control was accomplished using $50 \mathrm{~Hz}$ open-loop injection of $14 \%$ of the total fuel. In addition to recording the transient pressure signal, transient heat release was measured using a fiber-optic flame emission probe. Heat release measurements show that short duration fuel pulses produce a corresponding variation in the heat release, at the control frequency. Work in progress is aimed at identifying the specific parameters required for successful control, and understanding the observed sensitivity to various operating and geometric parameters.

\section{REFERENCES}

Candel, S. M. (1992). "Combustion Instabilities Coupled by Pressure Waves and Their Active Control," The Twenty-Fourth (International) Symposium on Combustion, pp. 1277-1296.

Harrje, D. T., and F. H. Reardon (1972). Liquid Propellant Rocket Combustion Instability, NASA SP-194.

Kenworthy, M. J., D. W. Bahr, P. Mungur, D. L. Burnus, J. M. Mehta, A. J. Cifone (1989). "Dynamic Instability Characteristics of Aircraft Turbine Engine Combustors," AGARD CP-450, ISBN 92-835-0503-4.

Kinsler, L. E., A. R. Frey, A. B. Coppens, and J. V. Sanders (1982). Fundamentals of Acoustics, Third edition, J. Wiley Publishers, p. 235.

Keller, J. O., and K. Saito (1987). "Measurements of the Combusting Flow in a Pulse Combustor," Combust. Sci. and Tech., Vol. 53, pp. 137-163.

Langhorne, P. J., A. P. Dowling, and N. Hooper (1990). "Practical Active Control System for Combustion Oscillations," J. Propulsion, Vol. 6, No. 3 pp. 324-333.

McManus, K. R., T. Poinsott, and S. M. Candel (1993). "A Review of Active Control of Combustion Instabilities," Prog. Energy Comb. Sci., Vol. 19. pp. 1-29.

Milosavljevic, V. D., A. M. Taylor, and J. H. Whitelaw (1990). "The Influence of Bumer Geometry and Flow Rates on the Stability of Swirl-Stabilized Nonpremixed Flames," Comb. and Flame, Vol. 80, pp. 196-208. 
Schadow, K. C., E. W. Hendricks, and R. J. Hansen (1992). "Recent Progress in the Implementation of Active Combustion Control," 18th ICAS Congress, Bejing, China, Sept 20-25, 1992. Proceedings, Vol. 1, Paper No. ICAS-92-2.5.3, pp. 942-952.

Schadow, K. C., K. J. Wilson, E. Gutmark, K. Yu, and R. A. Smith (1993). "Periodic Chemical Energy Release for Active Control," ISABE - International Symposium on Air Breathing Engines, 11th, Tokyo, Japan, Sept. 20-24, Vol. 1, pp. $479-485$.

Sivasegaram, S., and J. H. Whitelaw (1992). "Active Control of Combustors with Several Frequency Modes," ASME Winter Annual Meeting, Anaheim, CA, Nov. 8-13, 1992. Dynamic System and Control Division, Vol. 38, pp. 69-74.

Stamer, S. H., and R. W. Bilger (1986). "Joint Measurements of Velocity and Scalars in a Turbulent Diffusion Flame with Moderate Swirl," The Twenty-First Symposium (International) on Combustion, pp. 1569-1577.

FIGURES
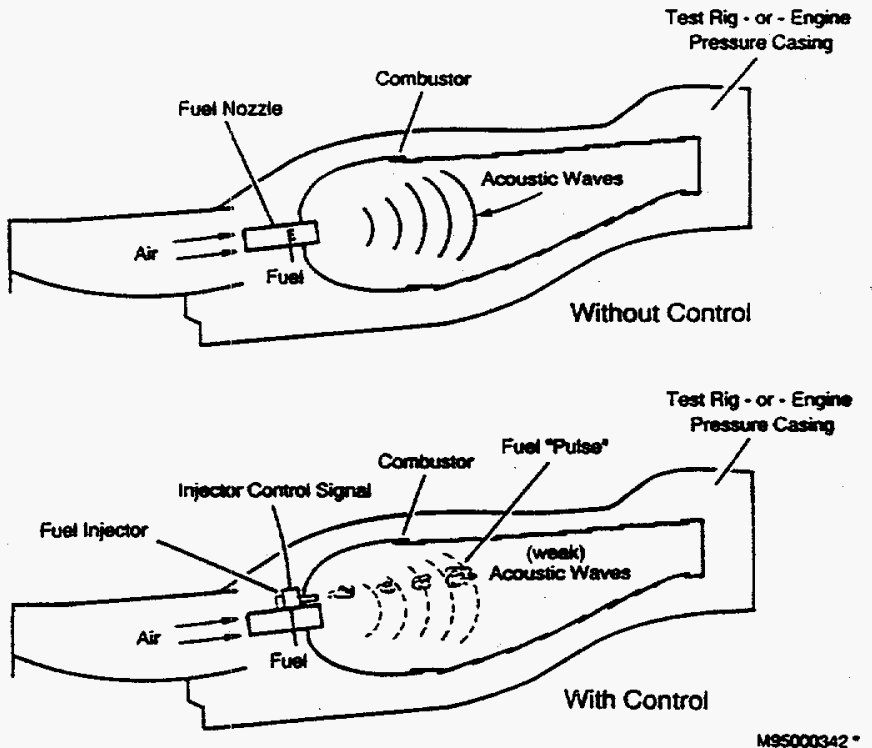

FIG. 1. SCHEMATIC OF ACTIVE CONTROL PROCESS USING PERIODIC FUEL INJECTION.

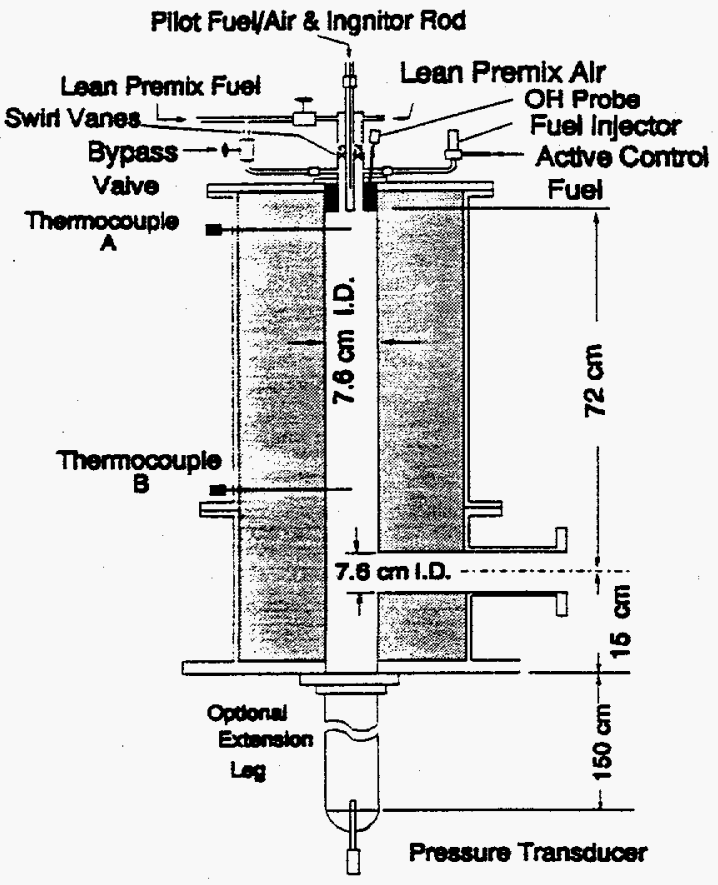

FIG. 2. EXPERIMENTAL CONFIGURATION.

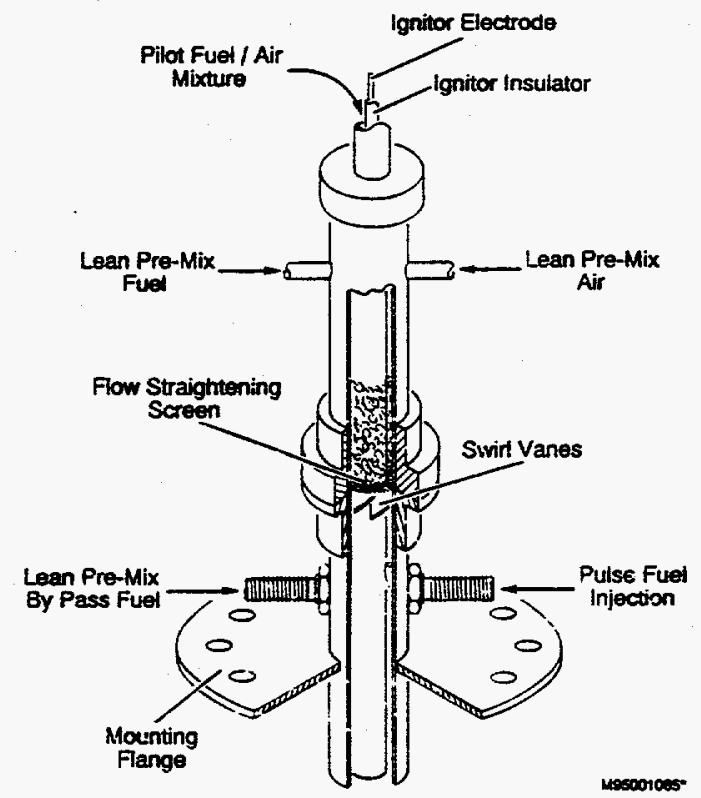

FIG. 3. DETAILED VIEW OF THE PREMIX FUEL NOZZLE. 


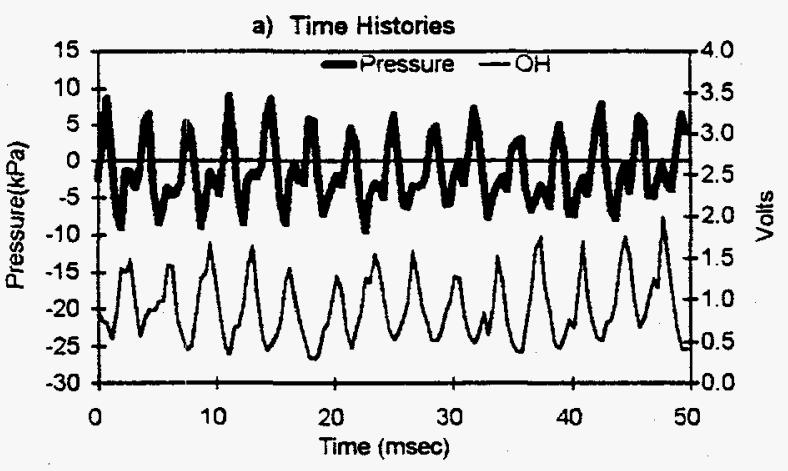

b) Spectral Density Function $\mathrm{G}$

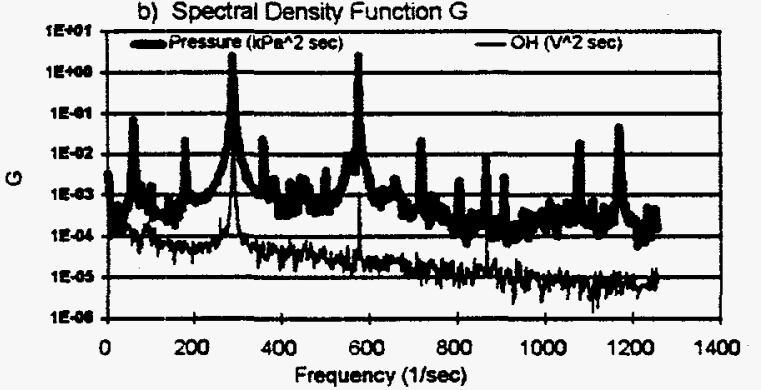

FIG. 4. TIME HISTORIES AND SPECTRA OF PRESSURE AND OH (HEAT RELEASE) SIGNALS WTH NO CONTROL FUEL.

a) PRESSURE

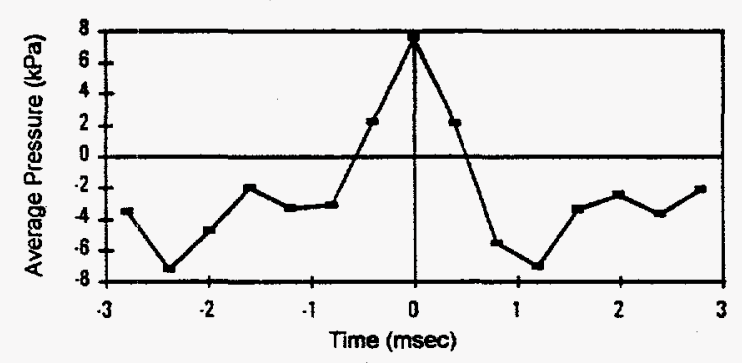

b) $\mathrm{OH}$

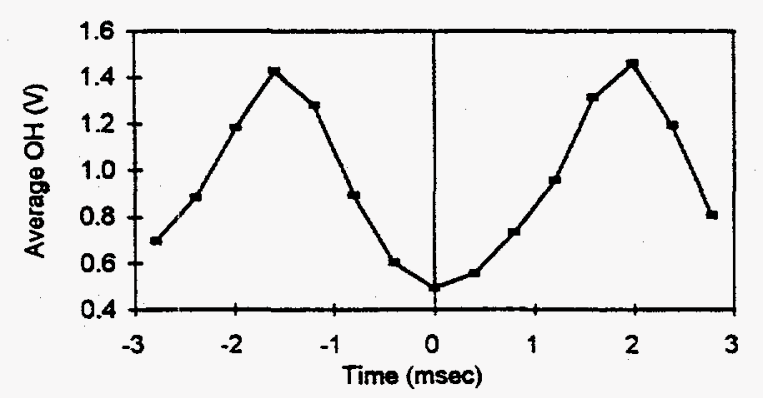

FIG. 5. ENSAMBLE AVERAGE OF A SINGLE CYCLE OF THE SIGNAL SHOWN IN FIG. 4.

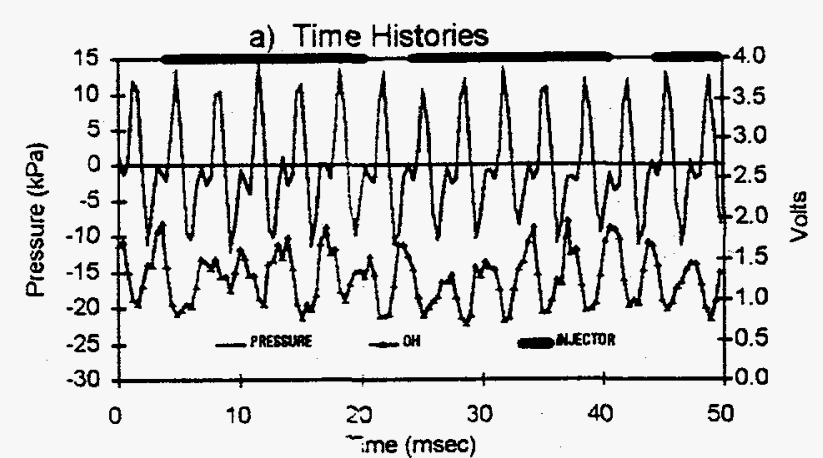

b) Spectral Density Function G

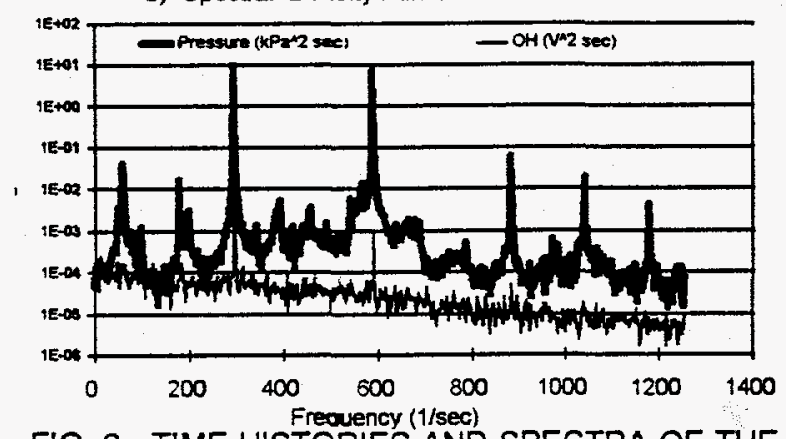

FIG. 6. TIME HISTORIES AND SPECTRA OF THE PRESSURE AND OH SIGNALS WTH $0.067 \mathrm{G} / \mathrm{S}$ CONTROL FUEL, 5OHZ. (THICK LINES IN (a) INDICATE PULSE WIDTH.)

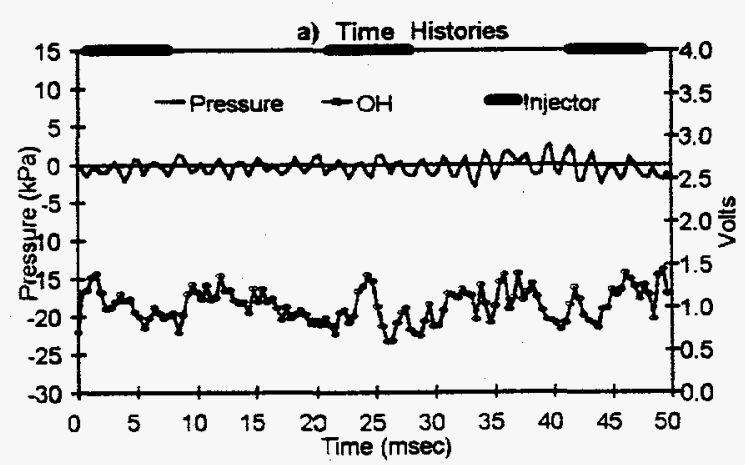

b) Spectral Density Function $G$

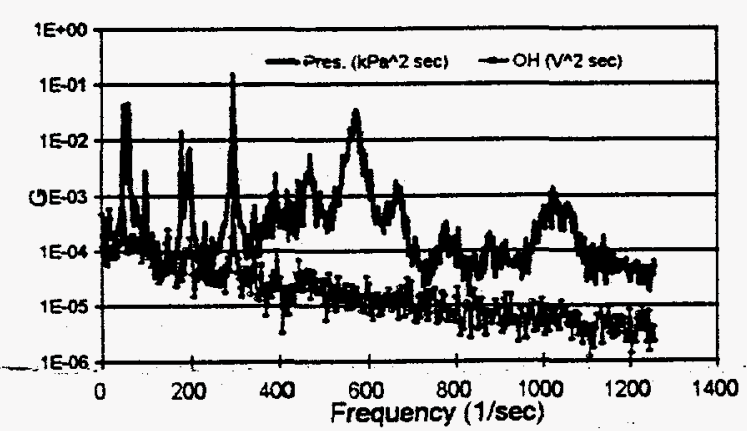

FIG. 7. TIME HISTORIES AND SPECTRA WTH NARROW PULSE WDTH AT CONDITIONS COMPARABLE TO FIG. 6. 


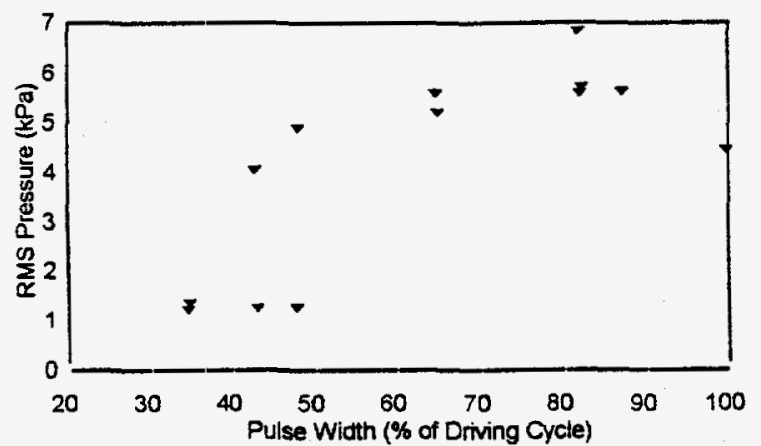

FIG. 8. EFFECT OF PULSE WIDTH ON COMBUSTOR DYNAMIC PRESSURE. 